\title{
Active tilting-pad journal bearings supporting flexible rotors: Part II-The model-based feedback-controlled lubrication
}

\author{
Salazar, Jorge Andrés González; Santos, Ilmar
}

Published in:

Tribology International

Link to article, DOI:

10.1016/j.triboint.2016.11.019

Publication date:

2017

Document Version

Peer reviewed version

Link back to DTU Orbit

Citation $(A P A)$ :

Salazar, J. A. G., \& Santos, I. (2017). Active tilting-pad journal bearings supporting flexible rotors: Part II-The model-based feedback-controlled lubrication. Tribology International, 107, 106-115.

https://doi.org/10.1016/j.triboint.2016.11.019

\section{General rights}

Copyright and moral rights for the publications made accessible in the public portal are retained by the authors and/or other copyright owners and it is a condition of accessing publications that users recognise and abide by the legal requirements associated with these rights.

- Users may download and print one copy of any publication from the public portal for the purpose of private study or research.

- You may not further distribute the material or use it for any profit-making activity or commercial gain

- You may freely distribute the URL identifying the publication in the public portal

If you believe that this document breaches copyright please contact us providing details, and we will remove access to the work immediately and investigate your claim 


\title{
Active Tilting-Pad Journal Bearings Supporting Flexible Rotors: Part II - The Model-Based Feedback-Controlled Lubrication
}

\author{
Jorge G. Salazar ${ }^{\mathrm{a}, \mathrm{b}}$, Ilmar F. Santos ${ }^{\mathrm{a}, *}$ \\ ${ }^{a}$ Department of Mechanical Engineering, Technical University of Denmark, 2800 Kgs. \\ Lyngby, Denmark \\ ${ }^{b}$ Department of Mechanical Engineering, University of La Frontera, Temuco, Chile
}

\begin{abstract}
This is part II of a twofold paper series dealing with the design and implementation of model-based controllers meant for assisting the hybrid and developing the feedback-controlled lubrication regimes in active tilting pad journal bearings (active TPJBs). In both papers theoretical and experimental analyses are presented with focus on the reduction of rotor lateral vibration. This part is devoted to synthesising model-based LQG optimal controllers ( $L Q R$ regulator + Kalman Filter) for the feedback-controlled lubrication and is based upon the mathematical model of the rotor-bearing system derived in part I. Results show further suppression of resonant vibrations when using the feedback-controlled or active lubrication, overweighting the reduction already achieved with hybrid lubrication, thus improving the whole machine dynamic performance.
\end{abstract}

Keywords: Tilting-Pad Journal Bearing, Actively-Lubricated Bearing, Active Vibration Suppression, Rotordynamics

\section{Introduction}

The control of vibration in rotating machinery has been achieved both passively and actively. Passive elements, such as squeeze-film dampers [1] and seal dampers [2] introduce dissipative forces to the system counteracting

\footnotetext{
*Corresponding author

Email addresses: jgsal@mek.dtu.dk (Jorge G. Salazar), ifs@mek.dtu.dk (Ilmar F.
} Santos) 
destabilizing forces and consequently reducing vibrations. However, without simultaneous sensing and actuating capabilities their potential to adapt and perform adequately in a wide frequency range becomes limited. The active elements overcome this limitation by incorporating actuators and sensors, which in a closed-loop configuration provide adaptability to wider frequency ranges and higher efficiency toward vibration reduction. Most of the active elements for rotating machines are built upon bearings. The control of vibrations is attained by modifying the bearing properties accordingly to the excitation loads and operational conditions. A variety of bearing types (ball bearings, magnetic bearings, compressible and incompressible fluid-film bearings) combined with several actuator types (magnetic, piezoelectric, pneumatic, hydraulic) leads to a variety of mechatronic devices or simply active bearings [3, 4, 5, 6, 7, 8, 9]. Herein, an incompressible fluid-film bearing with hydraulic actuator, namely tilting-pad journal bearings with active lubrication [10, 11, 12], is theoretically as well as experimentally investigated. The dynamic characteristics of rotors supported by TPJBs can be controlled either by modifying the journal-pad clearance through pad pushers - piezoelectric [13] or hydraulic [11] - or by direct modification of the fluid-film pressure distribution [14] via the active lubrication. In [15] the authors simulated an active TPJB with piezoelectric pushers controlled by an LQR regulator, while in [10] the author investigated the lateral dynamics of a rigid rotor controlled by pads on hydraulic pushers and introduced the active lubrication principle applied to TPJBs.

Active TPJBs aiming at improving damping properties and the stability margin of rotating machines have been theoretically investigated in [16, 17]. Bearing damping properties in active TPJBs are improved by featuring the feedback-controlled lubrication. Under this lubrication regime, the system response, namely the rotor lateral vibration, is utilized to generate suitable signals to command the servovalves that control the high pressurized oil flow. Synthesising PID controllers seems to be an adequate control design approach once the rotor-bearing system is manufactured. Some modelfree approaches [18, 19] or even "on-site" gain tuning can be used to obtain good controllers. The works [20, 21, 22, 23] are focused on PID controllers for active TPJBs. Nonetheless, if the synthesis of the controller is to be considered as a part of the machine design process, i.e. before the whole rotating machine is manufactured, then a model-based approach becomes an attractive control design tool, allowing for an optimization of the whole electro-mechanical system dynamics. The accuracy in describing the dy- 
namic behavior of passive TPJBs [24, 25, 26, 27, 28, 29] and active TPJBs connected to hydraulic servosystems [14, 30, 31, 32, 33. makes feasible today's model-based control design approaches. Regarding the active control of flexible rotors supported by fluid-film bearings, a theoretical study on full and reduced modal state controllers was presented in [34]. In [6] the vibration suppression was theoretically and experimentally studied though using magnetic actuators. Different state-feedback controllers were studied and the system model reduction was based upon retaining dominant modes; no spillover problems were observed. [35] also emphasizes the modal reduction of large rotordynamics systems whilst an LQR controller was designed. Linked with active TPJBs, in [36] a compressor supported by this kind of bearing was theoretically studied. Output feedback control and pole placement methods were used. In all these contributions the need for reducing the size of the rotordynamics model by modal approaches is addressed, which might lead to spillover problems.

The main contribution of this work is to present the design and implementation of a model-based controller for a flexible rotor supported by an activelylubricated TPJB. The objective of the controllers is to reduce the amplitude of the frequency response at resonance in closed-loop, while the TPJB is actively lubricated. From the theoretical standpoint, the rotor-bearing system modelling based on part I is hereby used. The model is modal-reduced and its states are further complex separated to design the LQG regulator. From an experimental standpoint, comparisons of the system response in closedloop with LQG against the PID controller are presented. Additional tests on slightly modified system are carried out to check the actuator bandwidth. Finally, a discussion on additional pinpointed dynamics is presented.

\section{Test Rig Facilities Recap}

The flexible rotor-bearing test rig was introduced in part I of this series of papers, more details can be found therein. It resembles a large overhung centrifugal compressor for which the rotor is supported by an activelylubricated TPJB as the one shown in Figure 11. The feedback-controlled regime, as defined in part I, is obtained by dynamically controlling the injection of pressurized oil directly into the bearing gap via servovalves. Three rotor configurations can be obtained by hanging different numbers of discs at the free-end, i.e. none, one or two discs. Consequently, three different levels of static bearing loading can be obtained, i.e. $400 \mathrm{~N}, 880 \mathrm{~N}$ or $1440 \mathrm{~N}$, 

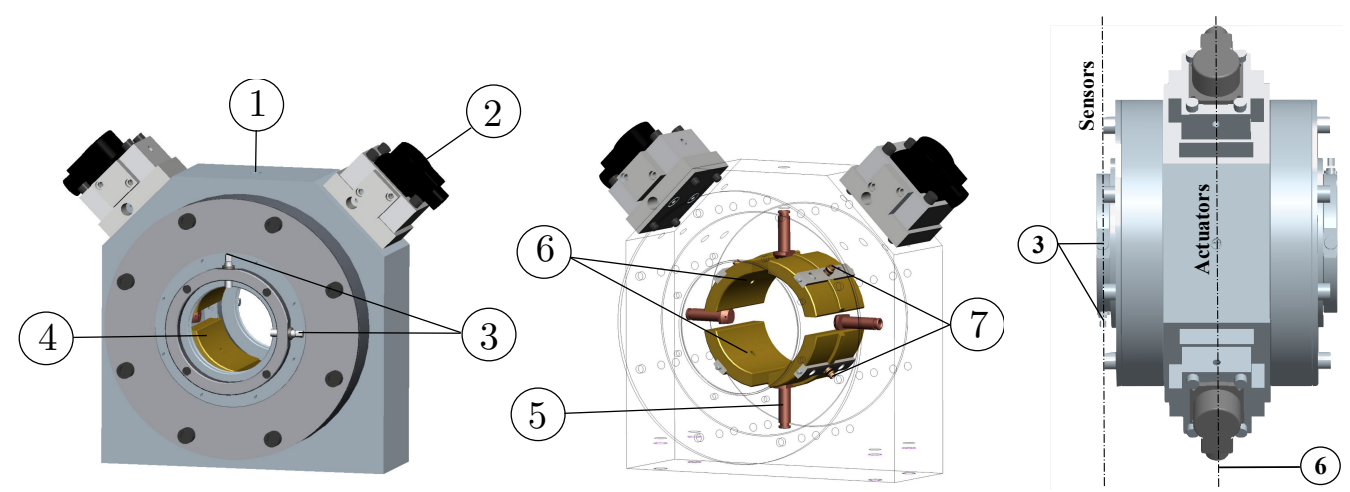

Figure 1: Active TPJB. (1) low pressure oil inlet. (2) electrohydraulic servovalve. (3) proximity probes. (4) pad. (5) low pressure oil nozzle. (6) centred pad orifice. (7) high pressure oil nozzle.

respectively. This also strengthens the gyroscopic effect due to the addition of the disc inertia and reduces the natural frequencies of the system. For instance, the first bending mode is reduced from $210 \mathrm{~Hz}$ to $150 \mathrm{~Hz}$ and 95 $\mathrm{Hz}$ by augmenting the disc number, respectively. The frequency bandwidth of the servovalves and consequently of the active forces strongly depends on the supply pressure $P_{s}$. For the current application high response servovalves are used, with a cutoff frequency of $350 \mathrm{~Hz}$ for a nominal pressure of $210 \mathrm{bar}$ and $260 \mathrm{~Hz}$ at $100 \mathrm{bar}$, the maximum design pressure for the current system.

\section{Linear Model of the Rotor-Bearing System}

The modelling of the flexible rotor-bearing system under different lubrication regimes was also presented in part I. The theoretical model is based on a finite element approach, in which each shaft element is represented by two nodes with 4 dofs each and where the active TPJB is included by using the full matrices of the dynamic linear coefficients obtained by an ElastoThermo-Hydrodynamic (ETHD) model of the bearing. In the case of the active lubrication regime, the equilibrium position $\Pi_{0}^{a}$ can be regarded as the same as in the hybrid lubrication regime, which is defined by the force and thermal equilibria as well as by the supply pressure of the injection system. Therefore, the linear equation of motion at a defined rotational speed $\Omega$ and a given supply pressure $P_{s}$ reads:

$$
\mathbf{M} \ddot{\mathbf{x}}+\left(\left.\mathbf{D}\right|_{\Pi_{0}^{a}}-\Omega \mathbf{G}\right) \dot{\mathbf{x}}+\left(\mathbf{K}+\left.\mathbf{K}\right|_{\Pi_{0}^{a}}\right) \mathbf{x}=\mathbf{W u}+\mathbf{f}_{e x t}
$$


where on the left hand side $\mathbf{M}, \mathbf{K}$ and $\mathbf{G}$ stand for the rotor mass, stiffness and gyroscopic matrices and $\left.\mathbf{K}\right|_{\Pi_{0}^{a}}$ and $\left.\mathbf{D}\right|_{\Pi_{0}^{a}}$ stand for the full dynamic coefficient matrices of the actively-lubricated bearing at the equilibrium condition $\Pi_{0}^{a}$, which include the servovalves dynamics. The generalized coordinated vector is composed of the rotor and active tilting pad dofs: $\mathbf{x}=$ $\left\{v_{1} w_{1} \gamma_{v_{1}} \gamma_{w_{1}} \ldots v_{n_{s}} w_{n_{s}} \gamma_{v_{n_{s}}} \gamma_{w_{n_{s}}}, \theta_{1} \ldots \theta_{n_{p}}, \ldots \beta_{1} \ldots \beta_{n_{p}}, \eta_{1} \ldots \eta_{n_{p}}, q_{v_{1}} q_{v_{2}}\right\}^{\top}$. On the right hand side, $\mathbf{f}_{\text {ext }}$ stands for the external forces applied to the rotor and $\mathbf{u}$ for the $2 \times 1$ control signal vector containing the driven voltage of each servovalve, i.e. $\mathbf{u}=\left\{u_{1} u_{2}\right\}^{\mathrm{T}}$. $\mathbf{W}$ is a sparse input control matrix whose non zero elements are defined by the servovalve parameters dependent on $P_{s}$ as:

$$
\mathbf{W}\left(i_{q_{v_{1}}}, 1\right)=\omega_{v_{1}}^{2} R_{v_{1}} \quad \mathbf{W}\left(i_{q_{v_{2}}}, 2\right)=\omega_{v_{2}}^{2} R_{v_{2}}
$$

Equation (1) can be rewritten as:

$$
\mathbf{M} \ddot{\mathbf{x}}+\overline{\mathbf{D}} \dot{\mathbf{x}}+\overline{\mathbf{K}} \mathbf{x}=\mathbf{W u}+\mathbf{f}_{e x t}
$$

\section{Modal-Reduced State-Space Model}

In order to design a model-based controller, the system governing equation (3) must be rewritten in a state-space formulation. To reduce computational burden when implemented, a pseudo-modal reduction scheme is chosen which considers only the slowest eigenvalues. As a consequence, a separation of complex states is needed for implementing the controller in real time processors, which does not work with complex numbers.

By choosing the state displacement and velocity vector $\mathbf{X}=\{\mathbf{x} \dot{\mathbf{x}}\}^{\top}$, the state-space representation of the LTI system of Equation (3) is written as:

$$
\begin{aligned}
\dot{\mathbf{X}} & =\mathbf{A X}+\mathbf{B u}+\mathbf{B}_{v} \mathbf{v}_{\mathbf{1}} \\
\mathbf{Y} & =\mathbf{C X}+\mathbf{v}_{\mathbf{2}}
\end{aligned}
$$

where for the state equation (4a) the state matrix $\mathbf{A}$, the input matrix $\mathbf{B}$ and the disturbance input matrix $\mathbf{B}_{\mathbf{v}}$ are defined as:

$$
\mathbf{A}=\left[\begin{array}{cc}
\mathbf{0} & \mathbf{I} \\
-\mathbf{M}^{-1} \overline{\mathbf{K}} & -\mathbf{M}^{-1} \overline{\mathbf{D}}
\end{array}\right] \quad \mathbf{B}=\left[\begin{array}{c}
\mathbf{0} \\
\mathbf{M}^{-1} \mathbf{W}
\end{array}\right] \quad \mathbf{B}_{v}=\left[\begin{array}{c}
\mathbf{0} \\
\mathbf{M}^{-1}
\end{array}\right]
$$

The external forces acting upon the system are considered as process or state disturbances $\mathbf{v}_{\mathbf{1}}=\mathbf{f}_{e x t}$. In the measurement equation (4b) the output matrix 
is defined as $\mathbf{C}=\left[\begin{array}{ll}\mathbf{I I} & \mathbf{0}\end{array}\right]$ where the matrix $\mathbf{I I}$ is a binary matrix with ones in the measured states. $\mathbf{v}_{\mathbf{2}}$ stands for the measurement noise.

Stability is assessed by the real part of the eigenvalues $\lambda_{i}$ which must be less than zero, i.e. $\Re\left\{\lambda_{i}\right\}<0$. Eigenvalues $\lambda_{i}$ and the correspondent right $\Phi_{i}$ and left $\Psi_{i}$ eigenvectors are obtained by solving the standard eigenvalue problems [37]:

$$
\mathbf{A} \Phi_{i}=\lambda_{i} \Phi_{i} \quad \mathbf{A}^{\top} \Psi_{i}=\lambda_{i} \Psi_{i}
$$

eigenvectors are normalized according to $\Psi_{i}^{\mathrm{T}} \Phi_{i}=1$. Controllability and observability are evaluated by the "degrees" of controllability and observability of the $i^{\text {th }}$ mode from the $j^{\text {th }}$ input or $k^{\text {th }}$ output, respectively, forming the $\cos A$ and $\cos B$ matrices whose elements are defined as [38]:

$$
\cos \left(\alpha_{i j}\right)=\frac{\left|\Psi_{i}^{T} \mathbf{b}_{j}\right|}{\left\|\Psi_{i}\right\|\left\|\mathbf{b}_{j}\right\|} \quad \cos \left(\beta_{k i}\right)=\frac{\left|\mathbf{c}_{k} \Phi_{i}\right|}{\left\|\mathbf{c}_{k}\right\|\left\|\Phi_{i}\right\|}
$$

This approach has been previously used in [39, 40] and is chosen over the standard invariant binary test based on the rank assessment [37] because it allows us to judge separately the controllability and observability of each mode. By taking the norm of each column of the $\cos A$ matrix and each row of the $\cos B$, gross measurement of controllability and observability are obtained by considering the contribution of all modes in the respective input $u_{i}$ and outputs $Y_{k}$.

The system as presented in Equation 4a is computationally heavy for implementing model-based controllers in real time since it requires a large number of states to be controlled. This is mainly due to the large number of shaft elements necessary to properly describe the rotor dynamics. In addition to that, a significant amount of dofs are added to describe the pad and hydraulic dynamics of the active TPJB. Therefore a system reduction is required. A number of reduction schemes can be used [41], however, the pseudo modal reduction is the most appropriate since only the lowest modes lying in the frequency range of interest are preserved while higher modes are discarded. Nonetheless, the model reduction is obtained at the expense of increasing the odds of producing observer or controller spillover problems 34 . Under this scheme the physical general coordinates are approximated by $n$ modal coordinates such that $\mathbf{X}=\mathbf{P}_{\mathbf{r}} \mathbf{q}$ and $\dot{\mathbf{X}}=\mathbf{P}_{\mathbf{r}} \dot{\mathbf{q}}$, for which the pseudomodal right and left matrices $\mathbf{P}_{\mathbf{r}}$ and $\mathbf{P}_{\mathbf{l}}$ are constructed column-wise with the selected modes as:

$$
\mathbf{P}_{\mathbf{r}}=\left[\begin{array}{lllll}
\Phi_{1} & \Phi_{2} & \Phi_{3} & \cdots & \Phi_{n}
\end{array}\right] ; \quad \mathbf{P}_{\mathbf{l}}=\left[\begin{array}{lllll}
\Psi_{1} & \Psi_{2} & \Psi_{3} & \cdots & \Psi_{n}
\end{array}\right]
$$


The system of equations (4) is rewritten as:

$$
\begin{aligned}
\dot{\mathbf{q}} & =\mathbf{A}^{r} \mathbf{q}+\mathbf{B}^{r} \mathbf{u}+\mathbf{B}_{v}^{r} \mathbf{v}_{\mathbf{1}} \\
\mathbf{Y} & =\mathbf{C}^{r} \mathbf{q}+\mathbf{v}_{\mathbf{2}}
\end{aligned}
$$

with:

$$
\mathbf{A}^{r}=\mathbf{P}_{\mathbf{1}}^{\mathrm{T}} \mathbf{A} \mathbf{P}_{\mathbf{r}} \quad \mathbf{B}^{r}=\mathbf{P}_{\mathbf{l}}^{\mathrm{T}} \mathbf{B} \quad \mathbf{B}_{v}^{r}=\mathbf{P}_{\mathbf{l}}^{\mathrm{T}} \mathbf{B}_{v} \quad \mathbf{C}^{r}=\mathbf{C P}_{\mathbf{r}}
$$

When making the similarity transformation with the pseudo-modal matrices $\mathbf{P}_{\mathbf{r}}$ and $\mathbf{P}_{\mathbf{l}}$, which contain complex valued modes, the resulting system matrices also become complex valued; therefore, a separation of complex states is needed in order to rewrite a real valued system that can be implemented in a computer, capable of processing only real numbers. The system is partitioned into real and imaginary parts as proposed in [39, 42] obtaining a double size $2 n$ system defined by the matrices:

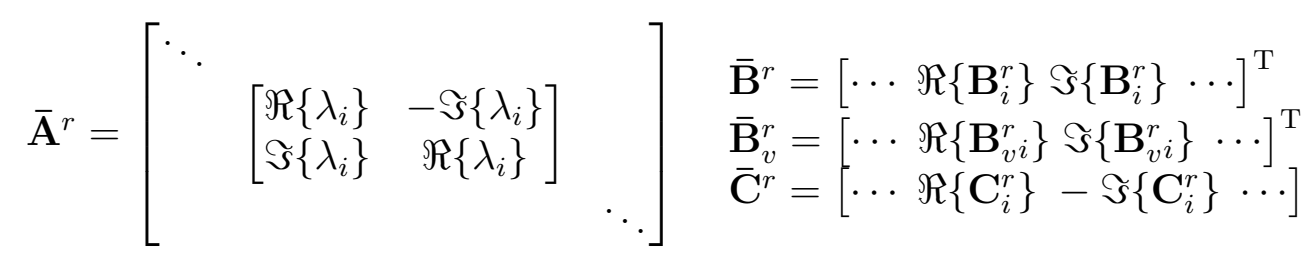

Provided that the eigenvalues are complex conjugated - no real eigenvalues - , the system can be downsized back to $n$ states by keeping in the matrices $\left\{\overline{\mathbf{A}}^{r}, \overline{\mathbf{B}}^{r}, \overline{\mathbf{B}}_{v}^{r}, \overline{\mathbf{C}}^{r}\right\}$ only the rows and columns associated with one of the conjugated eigenvalues and by multiplying by two the input matrices $\left\{\overline{\mathbf{B}}^{r}, \overline{\mathbf{B}}_{v}^{r}\right\}$. Therefore:

$$
\begin{aligned}
\dot{\mathbf{q}} & =\overline{\mathbf{A}}^{r} \mathbf{q}+\overline{\mathbf{B}}^{r} \mathbf{u}+\overline{\mathbf{B}}_{v}^{r} \mathbf{v}_{\mathbf{1}} \\
\mathbf{Y} & =\overline{\mathbf{C}}^{r} \mathbf{q}+\mathbf{v}_{\mathbf{2}}
\end{aligned}
$$

Equation 12 is the system representation in terms of the selected modal coordinates q. No correction for the steady-state error is made, assuming small contribution of higher modes to the steady state response. The reduced model can be used for designing controllers by influencing only the included system modes. 


\section{Controller Design}

With the availability of an LTI system model, the necessary controllers for developing the active lubrication with the TPJB can be part of the bearing design process. The control objective is to reduce vibrations in resonance zones, or in other words, to achieve FRF spectra that minimise peak responses. A Linear Quadratic Gaussian (LQG) regulator is to be designed by combining an optimal Linear Quadratic Regulator (LQR) with a stochastic optimal observer, the Kalman filter. Provided the system is stabilizable and taking advantage of the separation principle, the observer and controller can be indistinctly designed following the recommendations of [37].

In most practical applications only a few states can be measured, in this case up to four. This poses the need to estimate correctly the system states through observers. Two cornerstone works have paved the way for how observers are designed, the deterministic Luenberger observer [43] and the stochastic Kalman filter [44]. The observer used in the design of the LQG regulator corresponds to a full order Kalman filter. This stochastic observer, which takes into account the measurement $\mathbf{v}_{\mathbf{2}}$ and process $\mathbf{v}_{\mathbf{1}}$ noises, is the optimal observer for LTI systems provided the existence and propagation of noise. Even if the system does not behave linearly, it is the best estimator that can be designed. Referring to Figure 2 and using the system of equations (12), the defining equations of the observer are:

$$
\begin{aligned}
\dot{\hat{\mathbf{q}}} & =\overline{\mathbf{A}}^{r} \hat{\mathbf{q}}+\overline{\mathbf{B}}^{r} \mathbf{u}+\mathbf{L}(\mathbf{Y}-\hat{\mathbf{Y}}) \\
\hat{\mathbf{Y}} & =\overline{\mathbf{C}}^{r} \hat{\mathbf{q}}
\end{aligned}
$$

where $\mathbf{L}$ is the steady-state observer gain obtained in terms of the variance matrix $\mathbf{V}_{\mathbf{2}}$, the output matrix $\overline{\mathbf{C}}^{r}$ and the error covariance matrix, which is the solution of the time independent Riccati equation for the uncorrelated noise variance matrices $\mathbf{V}_{\mathbf{2}}$ and $\mathbf{V}_{\mathbf{1}}$ assumed for the measurement $\mathbf{v}_{\mathbf{2}}$ and process $\mathbf{v}_{\mathbf{1}}$ noises, respectively. Obtaining these matrices is the more challenging task in the design of the filter; the approach here utilized will be discussed later.

With the availability of the state estimates $\hat{\mathbf{q}}$, a full state-feedback controller can be designed. Full state-feedback means that the system output $\mathbf{Y}$ is used to reconstruct the entire "modal" state vector $\hat{\mathbf{q}}$ and not only the missing states. The LQR controller is an optimal control in terms of en-

ergy balance between states and control signals obtained by minimizing the 
steady-state cost function:

$$
\mathbf{J}=\int_{0}^{\infty}\left(\hat{\mathbf{q}}^{\top} \mathbf{Q} \hat{\mathbf{q}}+\mathbf{u}^{\top} \mathbf{R u}\right) d t
$$

where $\mathbf{Q}$ is a positive semi-definite $n \times n$ diagonal matrix utilized for weighting the states and $\mathbf{R}$ is a positive definite $2 \times 2$ matrix to weight the servovalve control signals. These matrices are obtained via trial and error tests through simulations until control requirements are met. This approach provides an intuitive way to synthesise the controller gains by weighting only the modal states of interest while control signals are kept within specifications. The control law is defined by:

$$
\mathbf{u}=-\mathbf{K} \hat{\mathbf{q}}
$$

where the control gain $\mathbf{K}$ is obtained in terms of the control weighting matrix $\mathbf{R}$, the input matrix $\overline{\mathbf{B}}^{r}$ and the solution of the steady-state Riccati equation for $\mathbf{Q}$ and $\mathbf{R}$. The control matrix $\mathbf{K}$ includes only proportional and derivative gains; integral action for keeping the system around the equilibrium can also be included in the calculation by means of system augmentation. In this case the state vector is augmented as $\mathbf{q}_{\mathbf{l q r}}=\left\{\hat{\mathbf{q}} \mathbf{q}_{i}\right\}^{\mathrm{T}}$ and the obtained gain matrix is $\mathbf{K}_{\mathbf{l q r}}=\left[\mathbf{K}-\mathbf{K}_{\mathbf{i}}\right]$. The integral states are defined as the integral of the output steady-state error and are incorporated via the time derivative equation $\dot{\mathbf{q}}_{i}=\mathbf{r}-\mathbf{Y}=\mathbf{r}-\overline{\mathbf{C}}^{r} \hat{\mathbf{q}}$, with $\mathbf{r}$ being the desired position reference.

Figure 2 shows the block diagram of the system in closed-loop, comprised of the rotor-bearing system plus the observer and the controller. The governing equations in closed-loop can be summarized as:

$$
\begin{aligned}
{\left[\begin{array}{c}
\dot{\mathbf{q}} \\
\dot{\mathbf{q}}_{i} \\
\dot{\hat{\mathbf{q}}}
\end{array}\right] } & =\left[\begin{array}{ccc}
\overline{\mathbf{A}}^{r} & \overline{\mathbf{B}}^{r} \mathbf{K}_{i} & -\overline{\mathbf{B}}^{r} \mathbf{K} \\
-\overline{\mathbf{C}}^{r} & \mathbf{0} & \mathbf{0} \\
\mathbf{L} \overline{\mathbf{C}}^{r} & \overline{\mathbf{B}}^{r} \mathbf{K}_{i} & \overline{\mathbf{A}}^{r}-\mathbf{L} \overline{\mathbf{C}}^{r}-\overline{\mathbf{B}}^{r} \mathbf{K}
\end{array}\right]\left[\begin{array}{c}
\mathbf{q} \\
\mathbf{q}_{i} \\
\hat{\mathbf{q}}
\end{array}\right]+\left[\begin{array}{c}
\mathbf{0} \\
\mathbf{I}_{r} \\
\mathbf{0}
\end{array}\right] \mathbf{r}+\left[\begin{array}{c}
\overline{\mathbf{B}}_{v}^{r} \\
\mathbf{0} \\
\mathbf{0}
\end{array}\right] \mathbf{v}_{\mathbf{1}} \\
\mathbf{Y} & =\overline{\mathbf{C}}^{r} \mathbf{q}+\mathbf{v}_{\mathbf{2}}
\end{aligned}
$$

for which the eigenvalues of the closed-loop system are determined by:

$$
\begin{aligned}
\operatorname{det}\left(\lambda \mathbf{I}-\left[\begin{array}{cc}
\overline{\mathbf{A}}^{r}-\overline{\mathbf{B}}^{r} \mathbf{K} & \overline{\mathbf{B}}^{r} \mathbf{K}_{i} \\
-\overline{\mathbf{C}}^{r} & \mathbf{0}
\end{array}\right]\right) & =0 \\
\operatorname{det}\left(\lambda \mathbf{I}-\left(\overline{\mathbf{A}}^{r}-\mathbf{L} \overline{\mathbf{C}}^{r}\right)\right) & =0
\end{aligned}
$$




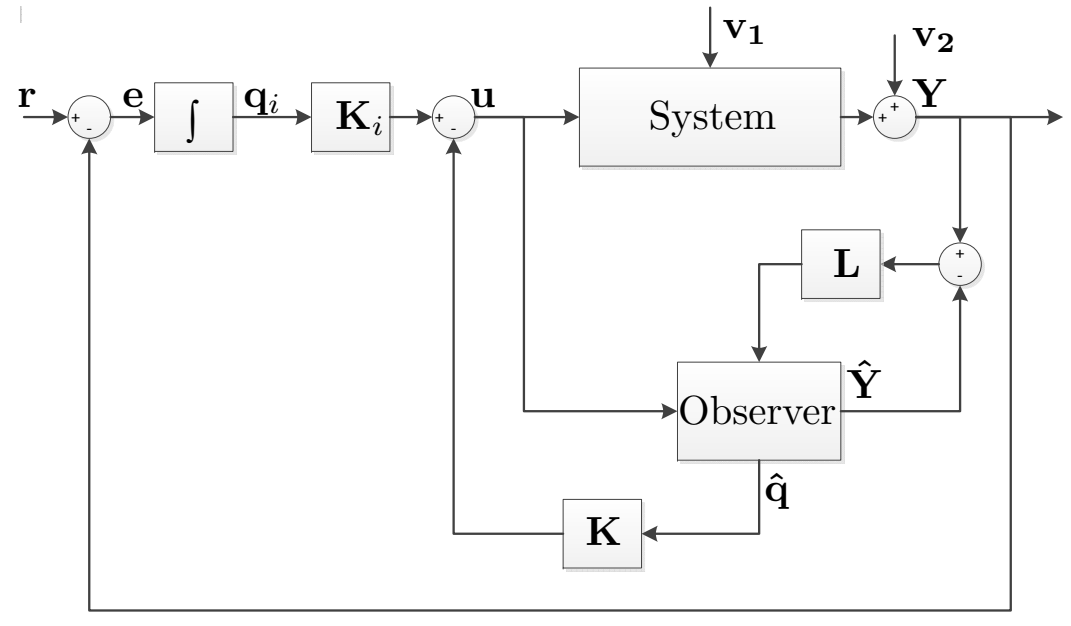

Figure 2: Closed-loop system block diagram. LQR controller gains $\mathbf{K}$ and $\mathbf{K}_{\mathbf{i}}$. Kalman filter with observer gain $\mathbf{L}$.

Equation (17a) and equation (17b) stand for the controller and observer eigenvalue equations respectively.

\section{Theoretical Results}

The system is firstly studied with the rotor without discs. Under this condition the first bending mode of the rotor-bearing system lies slightly above $200 \mathrm{~Hz}$. The static bearing load is $400 \mathrm{~N}$. The simulated operational conditions are $\Omega 1000 \mathrm{rpm}$ and $P_{s} 100 \mathrm{bar}$. The shaft discretization is reported in part I. In the current case, 26 finite elements ensure convergence of the shaft representation and place nodes at the more significant locations for the study. The rotor contributes 108 dofs whilst the active TPJB has 14 additional ones. There are three dofs per pad (tilt, bending and radial movement) plus one dof per servovalve. The full-order system has a total of 122 dofs, i.e. $4 n_{r}+n_{p} i_{p}+n_{v}$; it totalizes $2 N=244$ states which is reduced to $n=12$ modal states. The eddy-current sensors are installed at node 23 with sensors 1 and 2 and at node 17 with sensors 3 and 4 . Uneven sensors are horizontally oriented while even ones are vertically. The active TPJB is located at node 15 . The full order model can be reproduced with the information provided in the paper series. Table 1 summarizes the eigenvalues of the full model up to around $400 \mathrm{~Hz}$ and the ones kept in the reduced order model up to around $210 \mathrm{~Hz}$. The full order model is obtained considering the spool of 
the servovalve centred, i.e. injecting only the leakage flow. In the leftmost column an indication of the subsystem that the eigenvalues are related to are presented. To fulfil the complex separation approach, slow overdamped modes lying in the studied range are excluded in advance, hence they are not affected by the LQR controller. This is the same as not weighting them in the $\mathbf{Q}$ matrix and it contributes to lowering the reduced-order system size even more, critical for the controller implementation. The lower eigenvalues of around $10 \mathrm{~Hz}$ correspond to the rotor-bearing system conical mode which is very well damped. The next ones at $177 \mathrm{~Hz}$ are introduced by the servovalve dynamics, which have the larger damping ratio of the whole system. The highlighted frequencies around $210 \mathrm{~Hz}$ correspond to the first bending modes of the rotor-bearing system. These modes dominate the FRFs due to their relative low damping ratio. As a reference, higher bending modes are also depicted around $400 \mathrm{~Hz}$ for the full model.

Figure 3 shows the modal controllability degrees of the six retained modes in the reduced-order model, sorted as presented in Table 1 along with their conjugate, i.e. twelve states in total. The same sorting is utilized in subsequent figures of observability. It is clear that the included modes are more controllable from input 2 than from input 1 with gross measurements of controllability of $13 \cdot 10^{-4}$ and $1 \cdot 10^{-4}$, respectively, i.e. 13 times more controllable from input 2. From Figure 3 b) the most controllable mode corresponds to the servovalve mode. Among the rotor-bearing modes, conical modes are slightly more controllable than the bending ones. Regarding observability,

\begin{tabular}{|c|c|c|c|c|c|c|c|}
\hline & \multicolumn{3}{|c|}{ Full model } & & \multicolumn{3}{|c|}{ Reduced model } \\
\hline & $\lambda_{i}\left(\sec ^{-1}\right)$ & $\omega_{d_{i}}(\mathrm{~Hz})$ & $\zeta_{i}$ & & $\lambda_{i}\left(\sec ^{-1}\right)$ & $\omega_{d_{i}}(\mathrm{~Hz})$ & $\zeta_{i}$ \\
\hline 1) $R-B$ & $-55.22 \pm 64.09 \mathrm{i}$ & 10.20 & -0.653 & $\mathrm{R}-\mathrm{B}$ & $-55.22 \pm 64.09 \mathrm{i}$ & 10.20 & -0.653 \\
\hline 2) R-B & $-54.75 \pm 64.14 \mathrm{i}$ & 10.21 & -0.649 & $\mathrm{R}-\mathrm{B}$ & $-54.75 \pm 64.14 \mathrm{i}$ & 10.21 & -0.649 \\
\hline 3) SV & $-1188 \pm 1112.2 \mathrm{i}$ & 177 & -0.730 & 3) SV & $-1188 \pm 1112.2 \mathrm{i}$ & 177 & -0.730 \\
\hline 4) $\mathrm{SV}$ & $-1188 \pm 1112.2 \mathrm{i}$ & 177 & -0.730 & 4) $\mathrm{SV}$ & $-1188 \pm 1112.2 \mathrm{i}$ & 177 & -0.730 \\
\hline 5) R-B & $-66.27 \pm 1315.8$ & i 209.41 . & -0.050 & 5) R-B & $-66.27 \pm 1315.8$ & i 209.41 & -0.050 \\
\hline 6) R-B & $-66.33 \pm 1318.1 i$ & i 209.78 & -0.050 & 6) R-B & $-66.33 \pm 1318.1$ & i 209.78 & -0.050 \\
\hline 7) R-B & $-236.53 \pm 2588.1 \mathrm{i}$ & 411.89 & -0.091 & & & & \\
\hline 8) R-B & $-351.49 \pm 2589.8 \mathrm{i}$ & 412.18 & -0.090 & & & & \\
\hline
\end{tabular}

Table 1: Open-loop eigenvalues $\lambda_{i}$, damped frequencies $\omega_{d_{i}}$ and damping ratios $\zeta_{i}$ of the full and reduced order model of the rotor-bearing system. R-B: Rotor-Bearing system. SV: Servovalves, hydraulic system. 

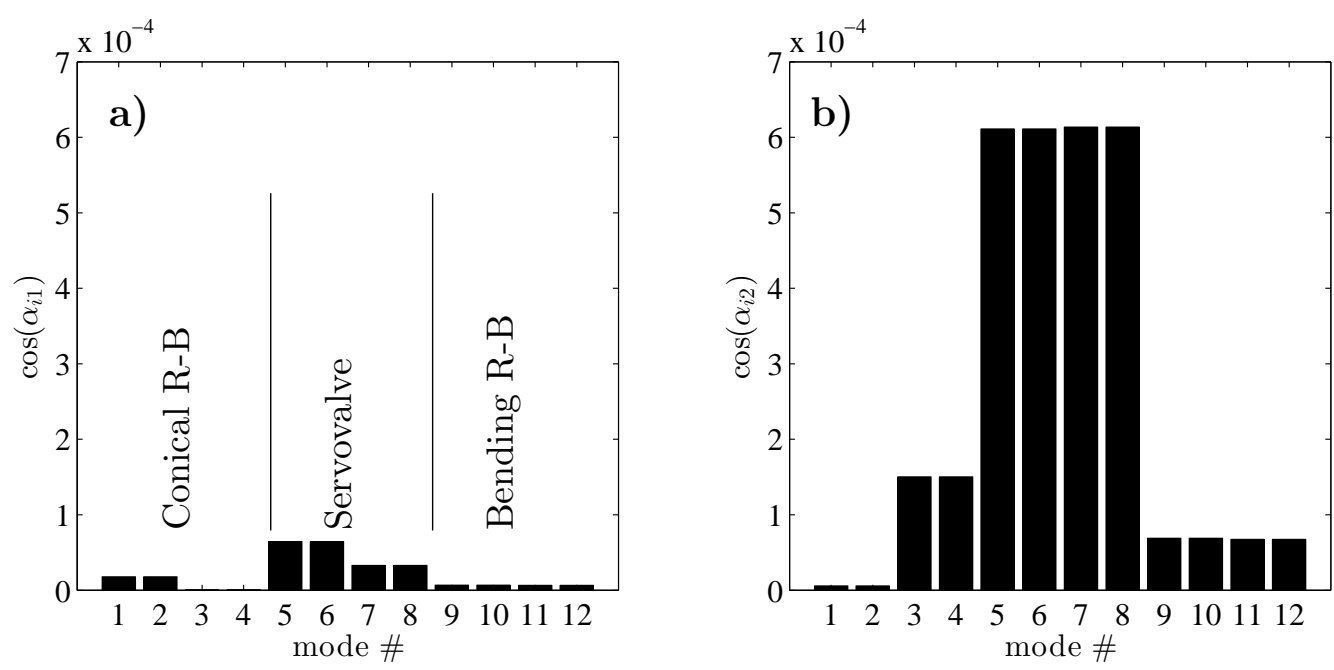

Figure 3: Modal Controllability degrees of the reduced-order model. a) from servovalve 1. b) from servovalve 2 .

Figure 4 depicts the degrees of observability from sensors 1, 2, 3 and 4 with gross measurements of observability of $19.1 \cdot 10^{-5}, 17.9 \cdot 10^{-5}, 15.4 \cdot 10^{-5}$ and $14.4 \cdot 10^{-5}$, respectively. Clearly the most observable mode corresponds to the conical one. On the other hand, the first bending mode is more observable from sensors 1 and 2 than from 3 and 4 . To diminish the computation burden, only sensors 1 and 2 are utilized in the controller design and in the experimental work to observe the bending mode. Servovalve modes are unobservables. A two input - two output plant is established.

The LQG regulator is designed for controlling the first bending mode of the rotor-bearing system in the no disc configuration. This implies that their corresponding modes $(1,2,5$ and 6$)$ are heavily penalized in comparison with the servovalve ones (3 and 4 ). The utilized $\mathbf{R}$ and $\mathbf{Q}$ matrices are presented in Equation (18). Some heuristic rules [37] were followed to determine the weights but they were finally determined after intensive trial and error tests. As mentioned, the rotor-bearing modes are highly penalized with the weights in the order of $10^{6}$, while the modes included by the servovalve modelling are quite less penalized by only 1 . The last two weights penalize the integral states. Control signals are weighted in a way that simulated signals are bounded $\pm 1.5 \mathrm{~V}$ to stick to the linear behaviour of servovalves while exciting 

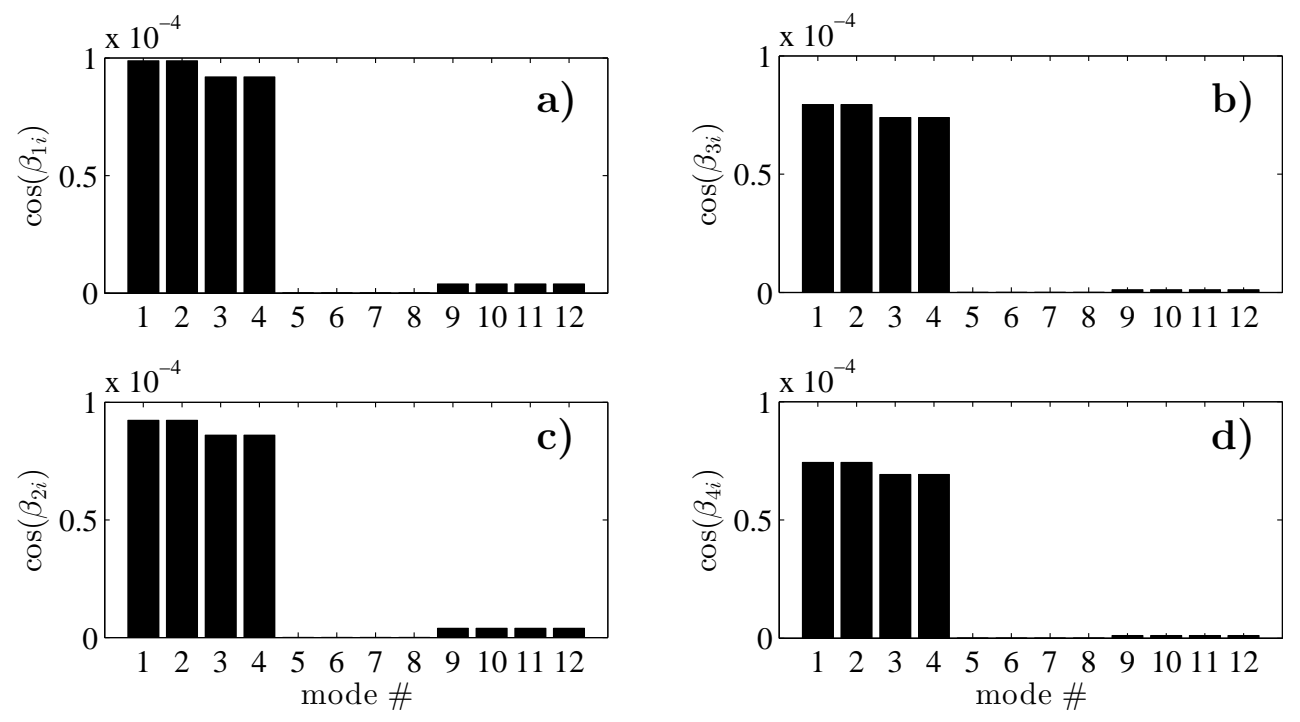

Figure 4: Modal observability degrees of the reduced-order model. a) from sensor 1. b) from sensor 3. c) from sensor 2. d) from sensor 4.

the system with a chirp signal.

$$
\begin{aligned}
& \mathbf{R}=\operatorname{diag}\left\{6 \cdot 10^{4}, 6 \cdot 10^{4}\right\} ; \\
& \mathbf{Q}=\operatorname{diag}\{\underbrace{8 \cdot 10^{6} 8 \cdot 10^{6}}_{1)} \underbrace{8 \cdot 10^{6} 8 \cdot 10^{6}}_{2)}, \underbrace{11}_{3)} \underbrace{1.8 \cdot 10^{6} 1.8 \cdot 10^{6}}_{4)} \underbrace{1.2 \cdot 10^{6} 1.2 \cdot 10^{6}}_{\text {5) }}, \underbrace{10^{9} 10^{9}}_{\text {Integral }}\} ;
\end{aligned}
$$

For the Kalman filter, the measurement and process noise covariance matrices are needed. The first one is readily obtained by characterizing statistically the sensors, while for the second one different approaches might be used. The first one consists of, provided a known covariance of the system disturbances, propagating the noise to the states through the disturbance input matrix $\mathbf{B}_{\mathbf{v}}$. Another form is to impose the noise to the states directly through an identity input matrix I [41]. This identity input matrix also has to be reduced following the same steps as for the input matrix $\mathbf{B}_{\mathbf{v}}$ in order to express the state noise in modal coordinates. Both options were simulated, with the last 
one obtaining better results. The noise covariance matrices are defined as:

$$
\begin{gathered}
\mathbf{V}_{\mathbf{2}}=\operatorname{diag}\left\{\left(1.422 \cdot 10^{-7}\right)^{2},\left(3.932 \cdot 10^{-7}\right)^{2}\right\} \quad\left[\mathrm{m}^{2}\right] \\
\mathbf{V}_{\mathbf{1}}=10^{5} \operatorname{diag}\{4,5,15,40,58475,17300,56734,3482,1059
\end{gathered}
$$

$$
2521,229,49,1453,5038\}
$$

In Figure 5 the theoretical FRFs of the full and reduced open-loop system as well as the reduced-order system in closed-loop are shown. It is seen that the reduced-order model reconstructs closely the full order one with small discrepancies towards the steady-state response. On the other hand, the vibration reduction in the resonant zone is achieved in both directions with the closed-loop reduced-order system, but at the expense of an increase in the system response at low frequencies. Table 2 summarizes the controller and observer eigenvalues of the closed-loop system. Unlike the pole placement approach in which, provided the system is stabilizable, eigenvalues can be modified at will, under optimal control they are obtained only after simulations. In closed-loop, one of the conical eigenvalues becomes overdamped, while for the other one the damping ratio is slightly increased. The servovalve eigenvalues remain almost unaltered. While for one of the first bending modes, the damped natural frequency is slightly reduced to around $200 \mathrm{~Hz}$ whilst its damping ratio is increased significantly. The last two eigenvalues are linked to integral action; they were obtained relatively slowly meaning

\begin{tabular}{lccccccc}
\hline & \multicolumn{3}{c}{ LQR regulator } & & \multicolumn{3}{c}{ Kalman Filter } \\
\cline { 2 - 3 } \cline { 7 - 8 } & $\lambda_{i}\left(\mathrm{sec}^{-1}\right)$ & $\omega_{d_{i}}(\mathrm{~Hz})$ & $\zeta_{i}$ & & $\lambda_{i}\left(\mathrm{sec}^{-1}\right)$ & $\omega_{d_{i}}(\mathrm{~Hz})$ & $\zeta_{i}$ \\
\hline 1) $\mathrm{R}-\mathrm{B}$ & -316.9 & - & - & & $-1.153 \cdot 10^{6}$ & - & - \\
2) $\mathrm{R}-\mathrm{B}$ & -92.03 & - & - & & $-0.2789 \cdot 10^{6}$ & - & - \\
3) $\mathrm{R}-\mathrm{B}$ & $-69.1 \pm 63.4 \mathrm{i}$ & 10.1 & -0.74 & & -103.41 & - & - \\
4) $\mathrm{SV}$ & $-1323 \pm 1104 \mathrm{i}$ & 176 & -0.768 & & -74.35 & - & - \\
5) SV & $-1188 \pm 1112 \mathrm{i}$ & 177 & -0.730 & & $-1188 \pm 1112 \mathrm{i}$ & 177 & -0.730 \\
6) $\mathbf{R}-\mathbf{B}$ & $\mathbf{- 7 2 6 . 3 5} \pm \mathbf{1 2 6 2 . 8 i}$ & $\mathbf{2 0 1}$ & $\mathbf{- 0 . 5 0}$ & & $-1188 \pm 1112 \mathrm{i}$ & 177 & -0.730 \\
7) $\mathbf{R}-\mathbf{B}$ & $\mathbf{- 1 2 2 . 8 7} \pm \mathbf{1 3 1 7 . 2 i}$ & $\mathbf{2 1 0}$ & $\mathbf{- 0 . 0 9}$ & & $-253.08 \pm 1280.5 \mathrm{i}$ & 203.8 & -0.181 \\
8) I & -0.0008 & - & - & & $-120.51 \pm 1308.4 \mathrm{i}$ & 208.3 & -0.092 \\
9) I & -0.0012 & - & - & & & & \\
\hline
\end{tabular}

Table 2: Closed-loop eigenvalues $\lambda_{i}$, damped frequencies $\omega_{d_{i}}$ and damping ratios $\zeta_{i}$ of the LQR regulator and Kalman filter observer. R-B: Rotor-Bearing system. I: integral action. 

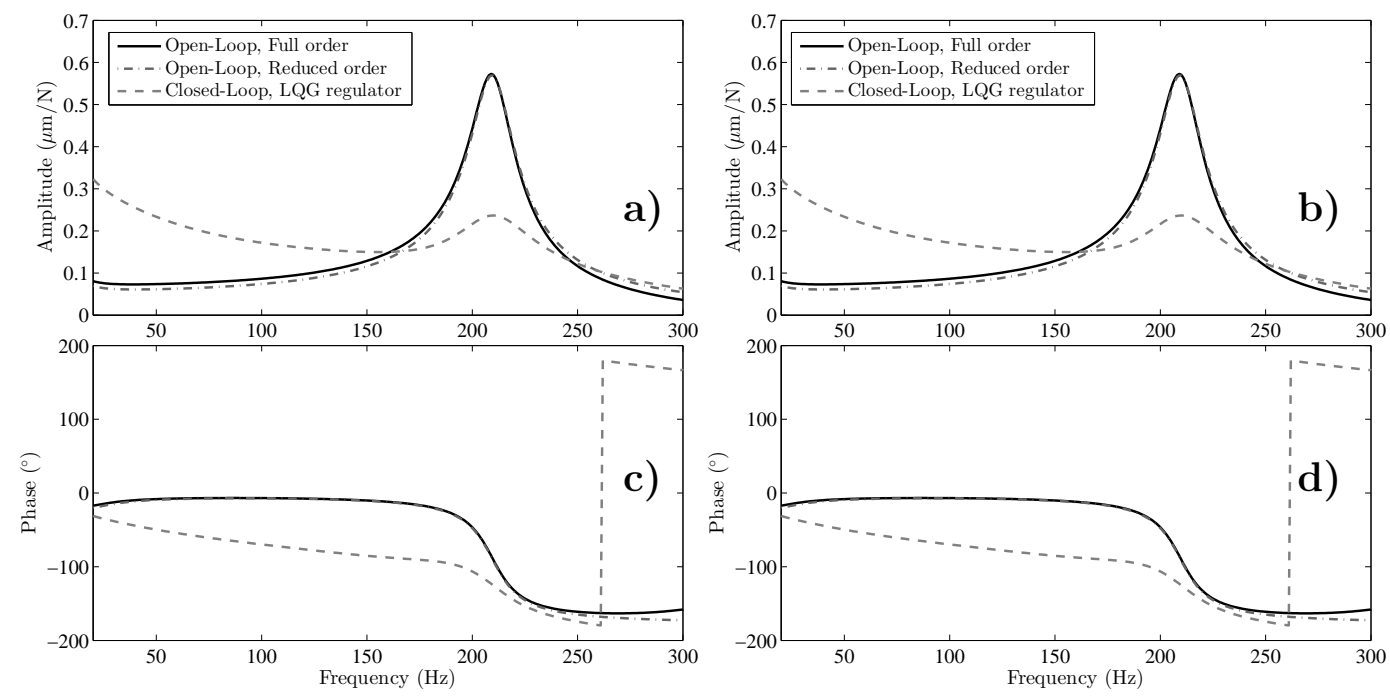

Figure 5: Theoretical FRFs in the Horizontal (a) and c)) and Vertical (b) and d)) direction. Solid line (-) corresponds to the open-loop full order system, i.e. system under hybrid lubrication. Dashed dotted line (-.) corresponds to the reduced-order model response. The dashed line (--) corresponds to the reduced-order system in closed-loop, i.e. featuring the LQG regulator.

that steady-state errors will be slowly compensated. Kalman filter features two fast real eigenvalues at the left half plane which dominates the observer dynamics.

\section{Experimental Results}

The experiments start when force and thermal equilibria were established for the same system configuration and operational conditions simulated. The implementation of controllers is carried out in discrete time considering a sampling frequency $F_{s}$ of $3 \mathrm{kHz}$. Results are presented only in the horizontal direction. The system is excited with an electromechanic shaker connected to the excitation bearing, corresponding to node 26 , dofs 101 . The system response is obtained at sensor pedestal 1, which corresponds to node 23, dofs 89 of the model. For obtaining the FRFs a chirp signal is swept in the frequency range covering the first bending frequency of the rotor-bearing system. The sweeping time was set to $10 \mathrm{~s}$ and the recording time was 5 min. Post processing parameters are: Hanning window, $1 \mathrm{~Hz}$ of frequency resolution and $50 \%$ of overlap. To avoid the onset of observer or controller spillover problems, low pass digital filters were implemented for filtering the 

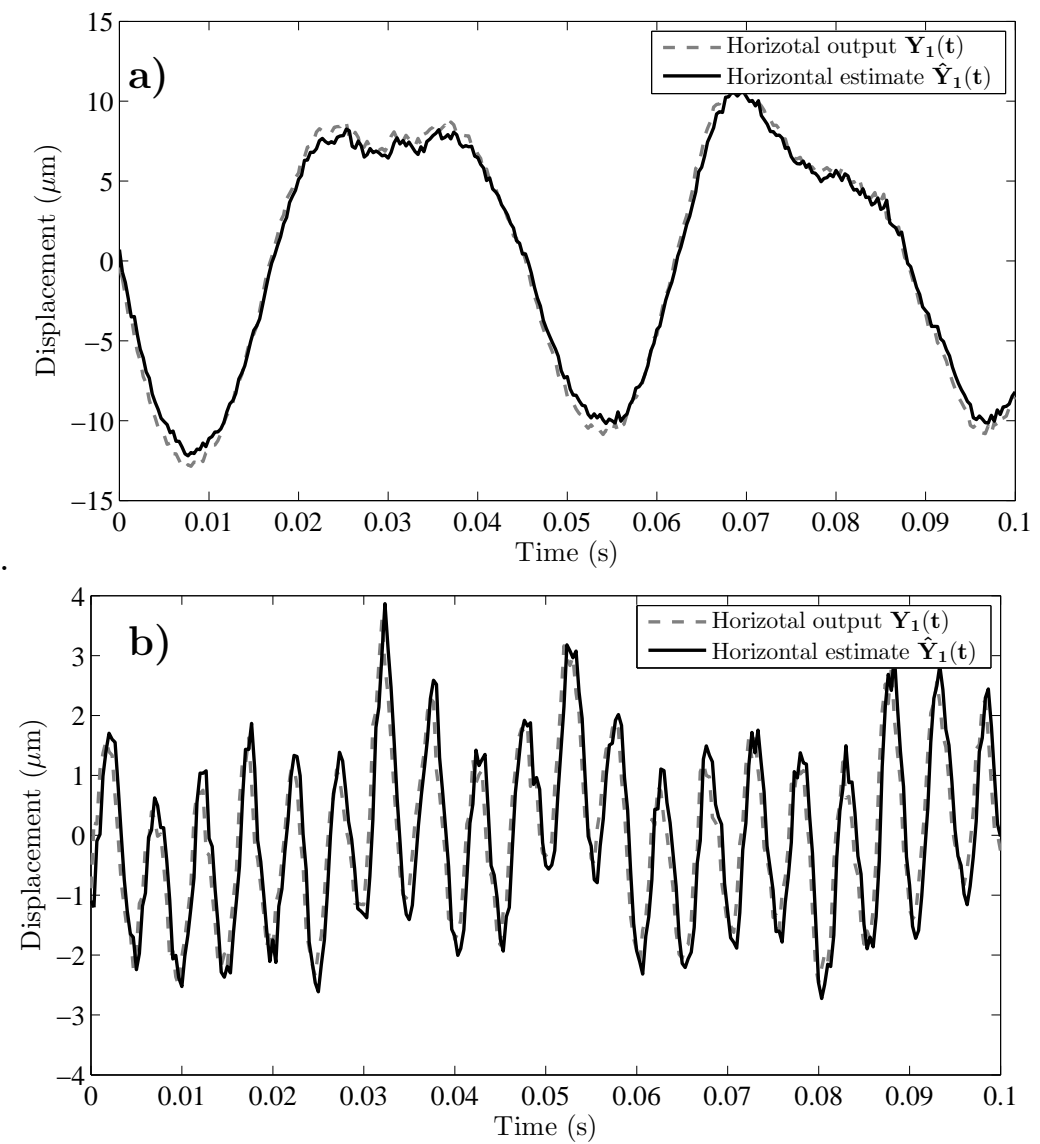

Figure 6: Time series of the system output and system estimate by the Kalman filter. a) low frequencies. b) high frequencies.

system outputs and control signals if required.

Figure 6 presents the system output $Y_{1}$ along with the corresponding estimate $\hat{Y}_{1}$ produced by the Kalman filter at low and high frequency ranges. Estimates correspond pretty well with the measurement which makes the observer a suitable one with regards the definitions of the covariance matrices $\mathbf{V}_{\mathbf{1}}$ and $\mathbf{V}_{\mathbf{2}}$, especially regarding the last one.

Figure 7 presents the results for the no disc configuration. In this case the resonance is slightly above $200 \mathrm{~Hz}$ and the active lubrication based upon the synthesised LQG controller and a variation of it were tested. This variant, the LQG*, ponders the first bending mode slightly less. No further im- 

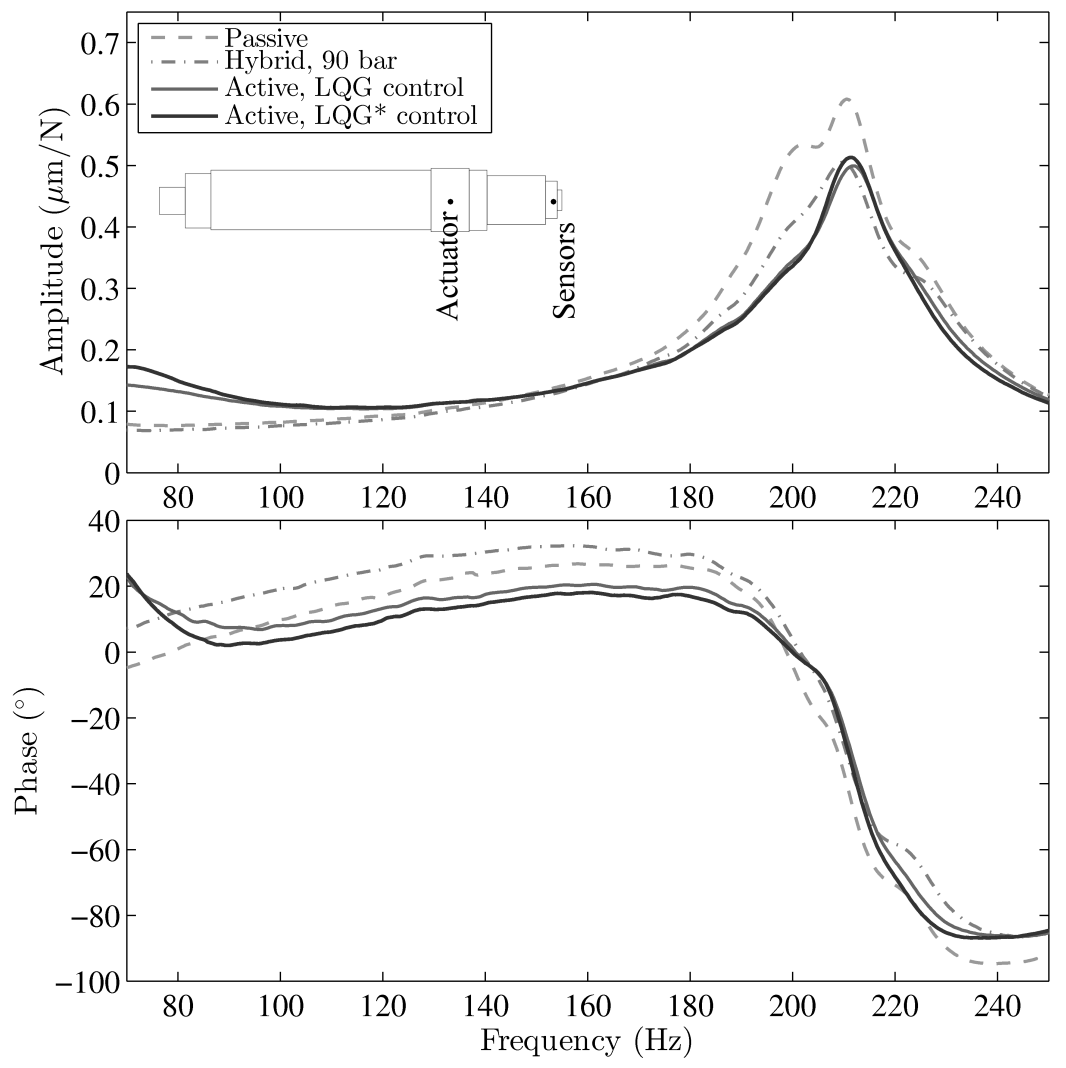

Figure 7: No disc configuration. Experimental FRF in the horizontal direction. $1000 \mathrm{rpm}$. 90 bar. Input at node 26 (dof 101) and output at node 23 (dof 89).

provements are obtained with the active lubrication and vibrations slightly differing from the hybrid case. This might be because servovalves are acting at their bandwidth limit for the 90 bar of supply pressure used. Under this supply pressure the natural frequency of the hydraulic system is around 250 $\mathrm{Hz}$ which, along with a 0.73 of damping factor, implies a decay in the servovalve response above $170 \mathrm{~Hz}$ approximately. To delve into this assumption the system is studied with the rotor hanging one disc and with the same supply pressure. Under this configuration the bearing supports a heavier load, $880 \mathrm{~N}$ approximately. Alongside, the damped natural frequency of the first bending mode of the rotor-bearing system is reduced to about $150 \mathrm{~Hz}$, which lies within the linear bandwidth of the actuator. Figure 8 shows the results in the horizontal direction for such a configuration and operational condition. 

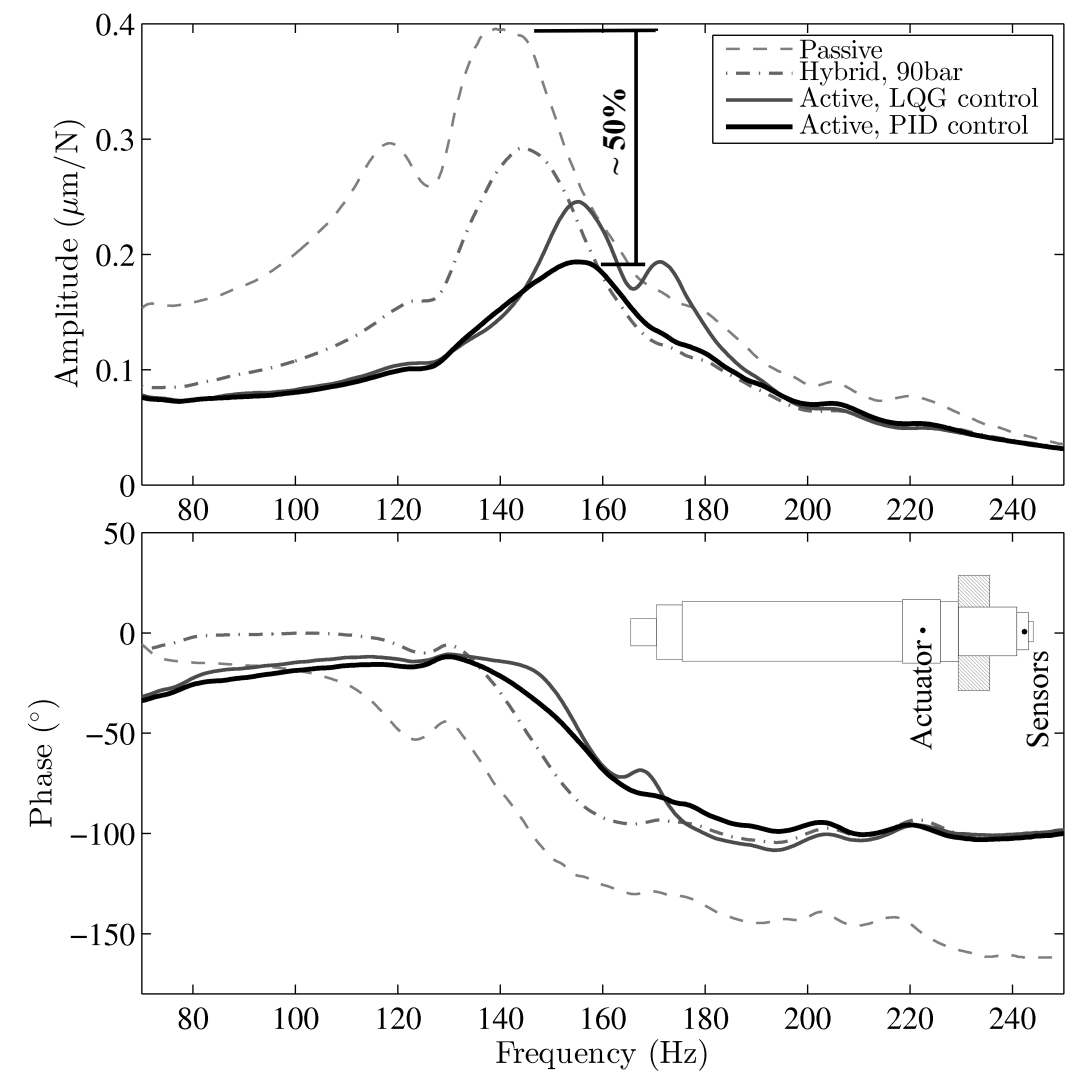

Figure 8: One disc configuration. Experimental FRF in the horizontal direction. 1000 rpm. 90 bar. Input at node 26 (dof 101) and output at node 23 (dof 89).

A new LQG controller was synthesised following the same procedure presented previously. In addition, for benchmarking purposes, an on-site tuned PID controller was also synthesised for developing the active lubrication in this configuration. The proportional, derivative and integral matrices were defined as $\mathbf{K}_{\mathbf{p}}=10^{3}[7-7 ; 77](\mathrm{V} / \mathrm{m}), \mathbf{K}_{\mathbf{d}}=[50-40 ; 4050](\mathrm{Vs} / \mathrm{m})$ and $\mathbf{K}_{\mathbf{i}}=10^{4}[1-1 ; 11](\mathrm{V} / \mathrm{ms})$, respectively. The tuning of an appropriate PID controller is not trivial and an important amount of trial and error tests are run until obtaining a performance that met the requirements. It is noted that the tendency in the results remains, in the sense that vibrations are reduced with the hybrid lubrication regime when compared against the passive one. But in this case further reductions are obtained with the active lubrication, which performs slightly better with PID control rather than with the LQG 

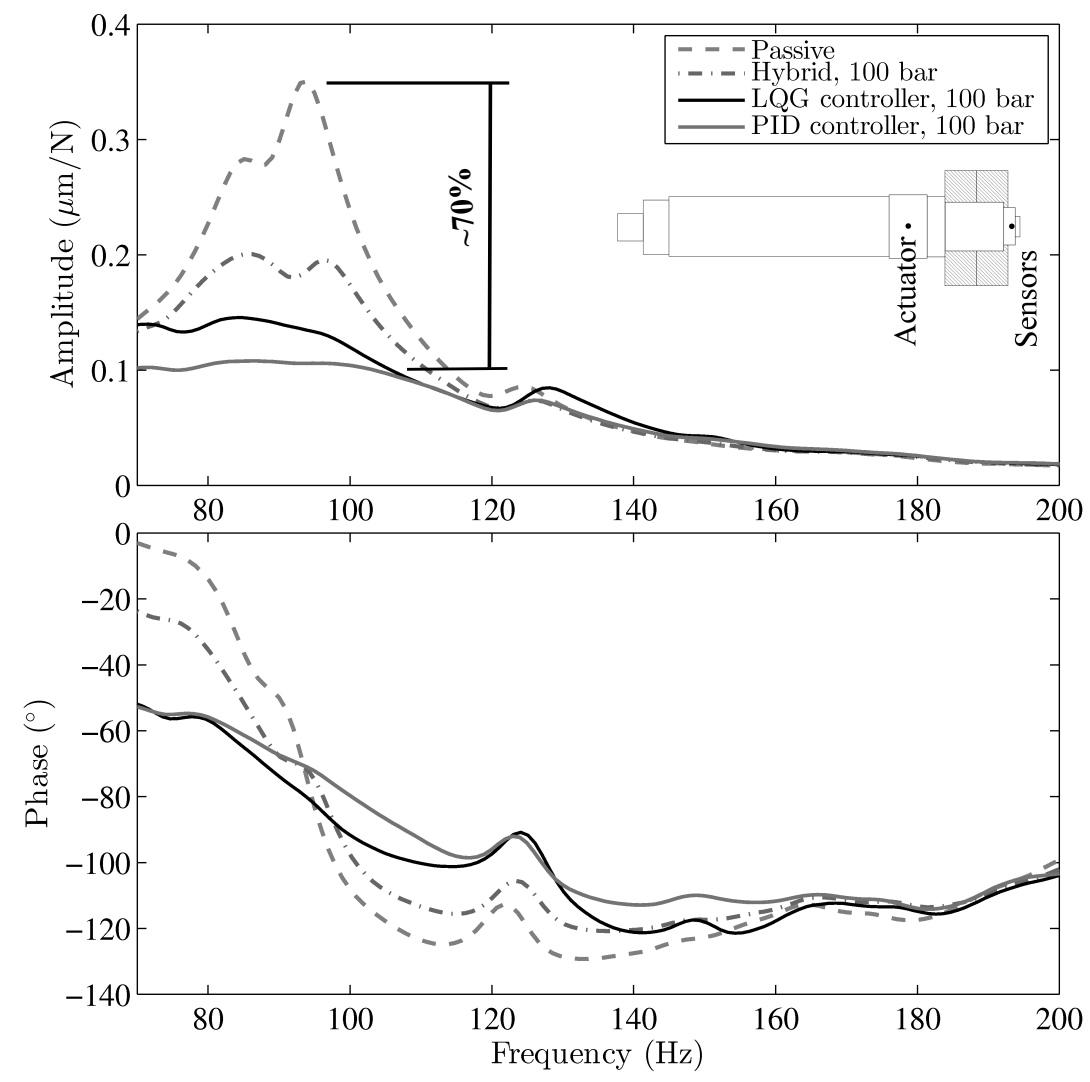

Figure 9: Two discs configuration. Experimental FRF in the horizontal direction. 1000 rpm. 100 bar. Input at node 26 (dof 101) and output at node 23 (dof 89).

regulator. Nonetheless, reductions are still not so significant.

To further reduce in frequency the resonant zone and ensure a better actuator performance, an additional disc was mounted, obtaining two discs hanging in the rotor. Static bearing load increases up to $1440 \mathrm{~N}$. The supply pressure was slightly increased to 100 bar. Figure 9 depicts the experimental FRFs obtained with both controllers, the same PID controller and a new synthesised LQG regulator. Again, the same synthesising procedure presented in the theoretical section was followed. Additionally, the system response under passive and hybrid lubrication is also included for comparison. Under the hybrid lubrication, the spool is kept centred and only the leakage flow into the bearing clearance occurs. A significant reduction in amplitude is obtained in the resonant zone when the hybrid lubrication is featured in 

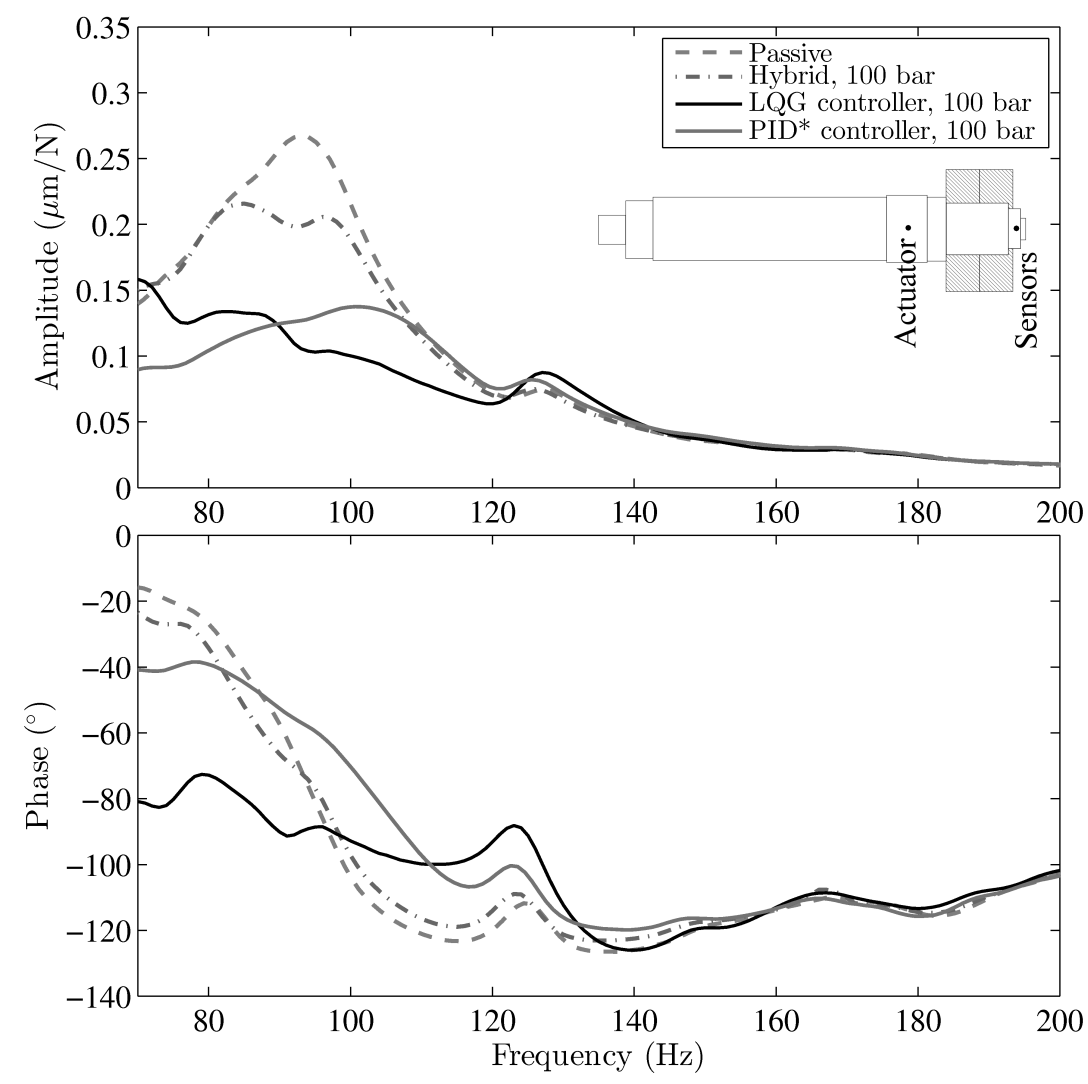

Figure 10: Two discs configuration. Experimental FRF in the horizontal direction. 2000 rpm. 100 bar. Input at node 26 (dof 101) and output at node 23 (dof 89).

comparison with the passive or conventional one. This is due to the injection of high pressurized oil at 100 bar which modifies the bearing stiffness and damping properties. Further reductions are obtained in the resonant zone with the LQG regulator and even more with the PID controller. A fitting of a single degree of freedom curve to the passive and active - with LQG control - cases reveals an increase of the damping ratio of approximately five times, from 0.067 to 0.33 , which is half of that predicted. Doubtless, a better performance of the actuator is obtained when two discs are hanged on the rotor than when is only one. As a point of comparison, in Figure 9 a peak reduction of about $70 \%$ is obtained with active lubrication based on PID control when compared to the passive one, whereas in Figure 8 this reduction is only of the order of $50 \%$. 


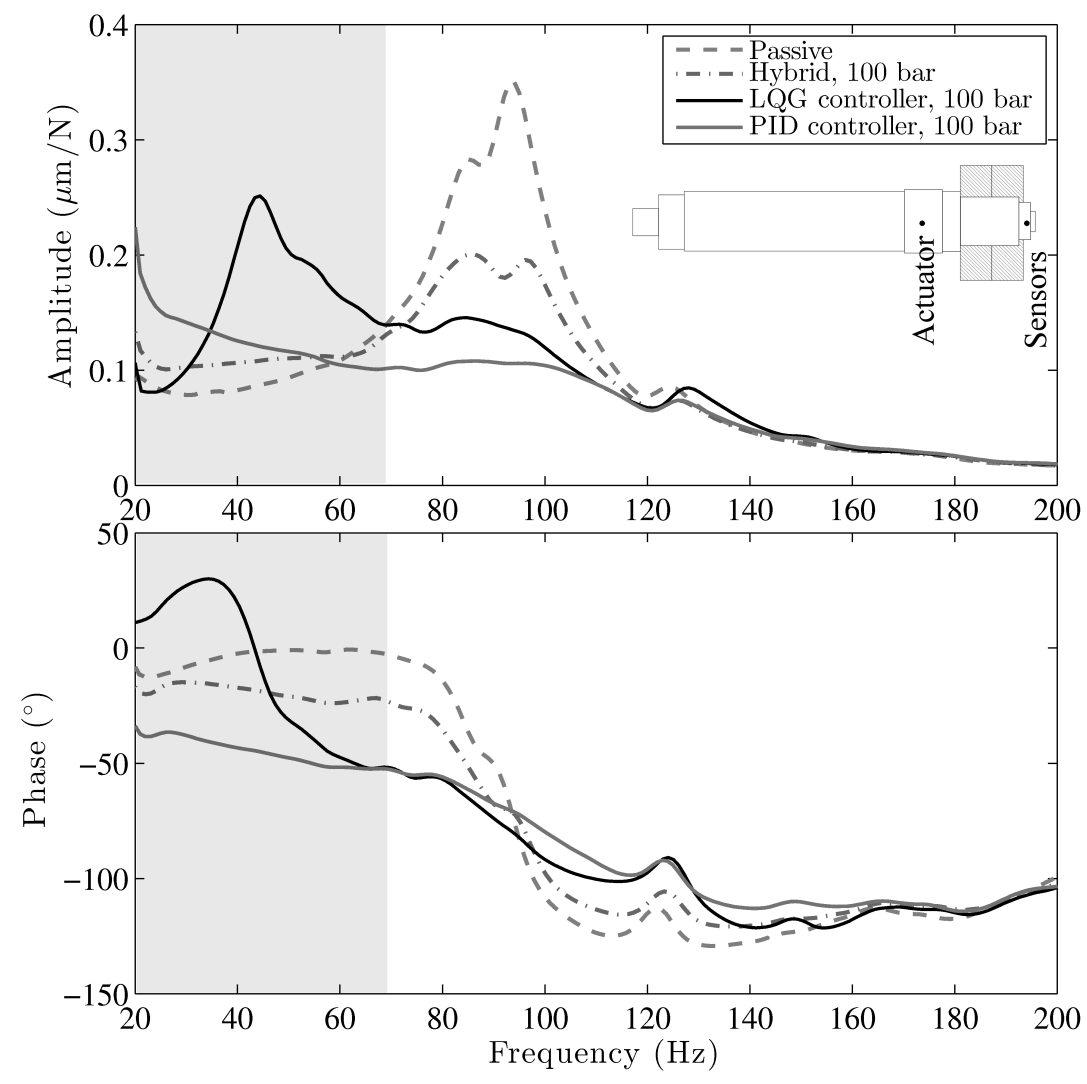

Figure 11: Two discs configuration. Experimental FRF in the Horizontal Direction. 1000 rpm. 100 bar. Input at node 26 (dof 101) and output at node 23 (dof 89).

Despite the LQG controllers being designed for an angular speed of 1000 rpm, in this configuration it was also tested at a higher speed. Figure 10 shows such results for $2000 \mathrm{rpm}$. The PID controller was retuned in order to meet the requirement of reducing vibrations at such velocity. The proportional and derivative gain matrices were updated to $\mathbf{K}_{\mathbf{p}}=10^{4}[1-1 ; 11]$ $(\mathrm{V} / \mathrm{m})$ and $\mathbf{K}_{\mathbf{d}}=[20-10 ; 1020](\mathrm{Vs} / \mathrm{m})$. It can be noticed that in general the vibration amplitudes reduce and both controllers manage to reduce the vibration amplitudes around the $90 \mathrm{~Hz}$ resonance. The PID controller still performs better than the LQG regulator. In all studied cases, no spillover problems at higher frequencies were observed for the model-based controllers, hence signal filtering was not needed. 


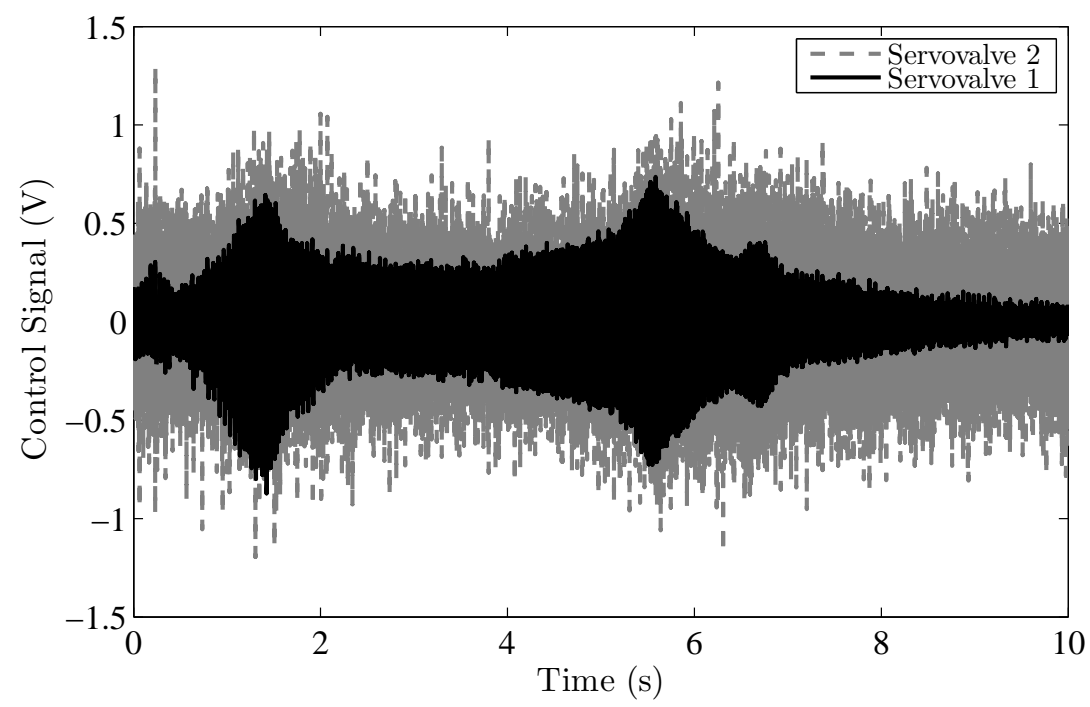

Figure 12: Servovalve control signals for the LQG controller during a $10 \mathrm{~s}$ sweep of a 20-200 Hz chirp signal.

\section{Discussion}

Previous results have achieved the control goal of reducing the vibrations in the frequency range for which the controllers were designed, i.e. around the resonant zone of the first bending frequency of the rotor-bearing system. However, at lower frequencies than $70 \mathrm{~Hz}$, the implementation of the LQG regulators yields an unexpected resonance which only shows up with this sort of controller. Figure 11 depicts the same results as Figure 9 but extended at low frequencies up to $20 \mathrm{~Hz}$ (highlighted with light a gray transparent layer). Frequencies below this value are avoided due to the seismic mass behaviour of the shaker. The resonant zone is identified at around $40 \mathrm{~Hz}$ only for the LQG controller. It is also confirmed that the active lubrication based on the PID controllers perform well at low frequencies with only a small amplification of rotor vibration amplitudes close to $20 \mathrm{~Hz}$. Figure 12 depicts the voltage control signals commanding the servovalves when performing the tests with the LQG regulator. The rise in amplitude of the servovalves clearly noted in servovalve 1 before 2 seconds corresponds to such a $40 \mathrm{~Hz}$ resonance. It is also seen that signals are bounded between $\pm 1 \mathrm{~V}$ and that control signal 2 is larger and noisier. Since the performance significantly deteriorates below $70 \mathrm{~Hz}$ only for the LQG controller, it is assumed that there are unmodelled 


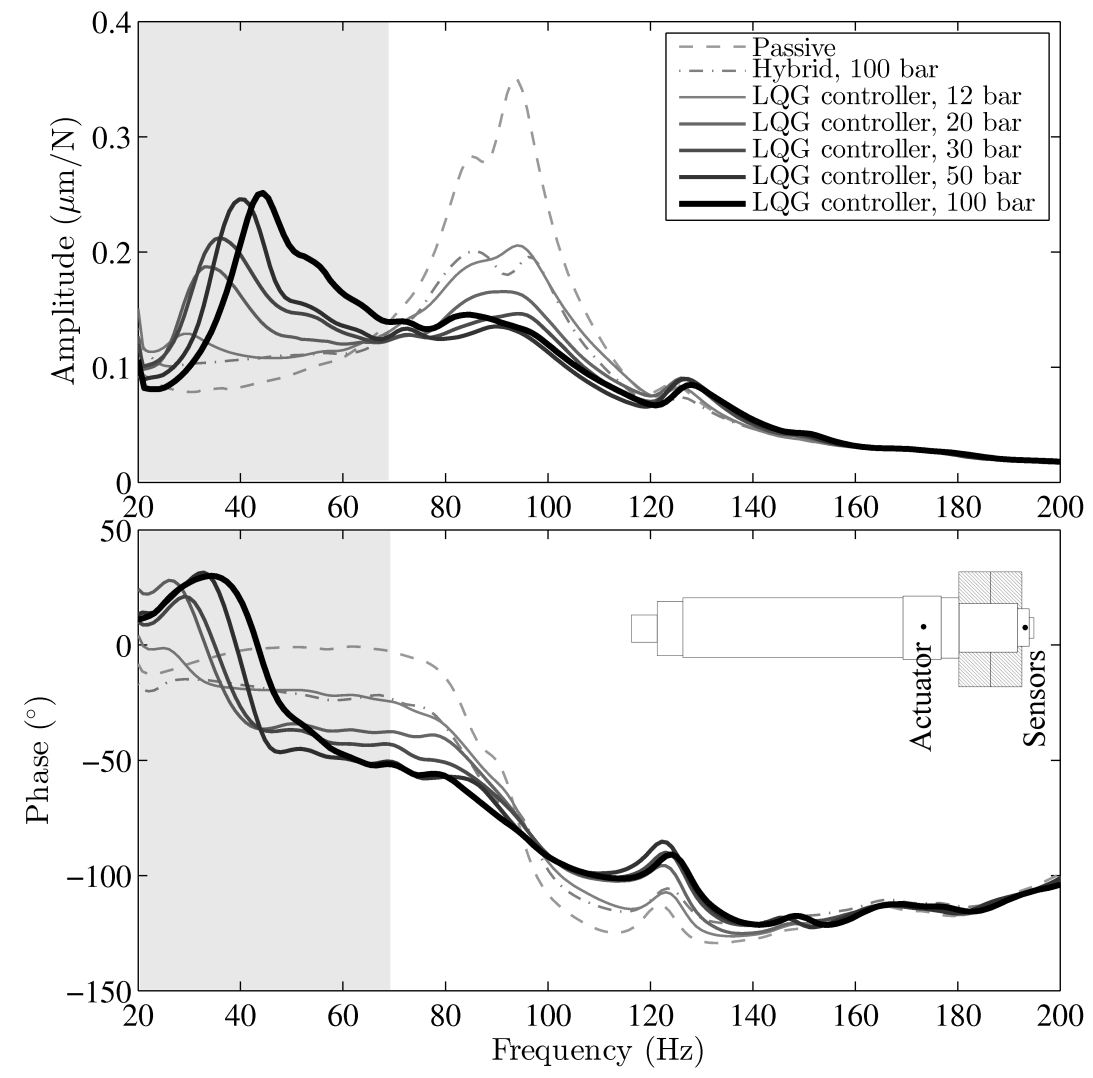

Figure 13: Two discs configuration. Experimental FRF in the Horizontal Direction. 1000 rpm. Input at node 26 (dof 101) and output at node 23 (dof 89). Effect of the supply pressure in the performance of the LQG regulator. 12, 20, 30, 50 and 100 bar.

dynamics. To explore the possible causes, the supply pressure $P_{s}$ is varied to make the controller less aggressive, even though the controller is originally designed for 100 bar. According to the servovalve specifications, a reduction of the pressure supply implies to lessen the servovalve natural frequency and hence obtain a narrower bandwidth of effectiveness.

Figure 13 shows the effect of reducing the supply pressure $P_{s}$ in the radial oil injection system. It is noticed that as the pressure reduces, the frequency and amplitude of the resonant zone around $40 \mathrm{~Hz}$ also reduces. It is also evident that as the pressure reduces the effectiveness of the controller around 90 $\mathrm{Hz}$ (rotor-bearing resonance) deteriorates as expected. It is believed that this is due to a strong interaction between the rotor-bearing system with 


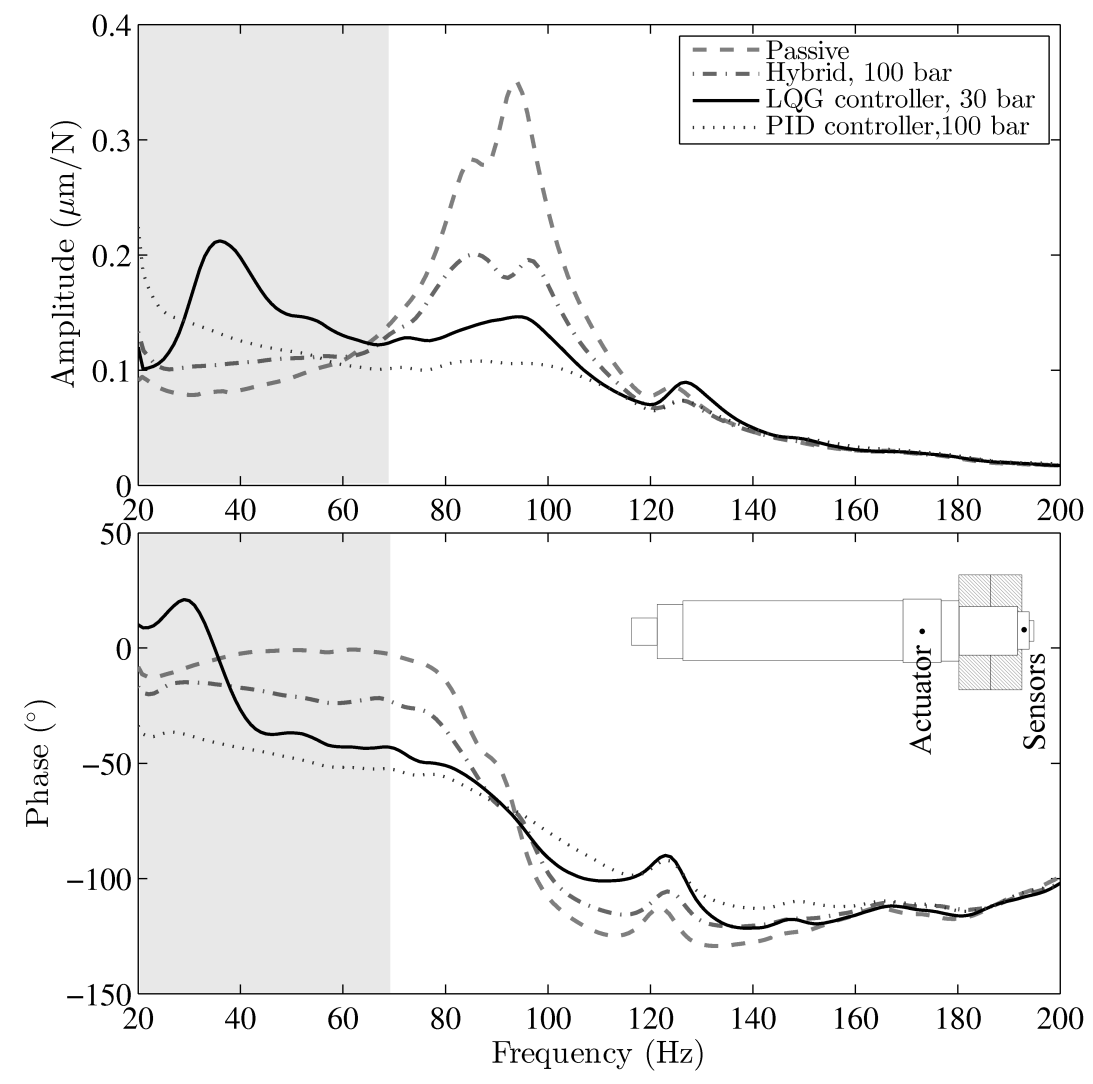

Figure 14: Two discs configuration. Experimental FRF in the Horizontal Direction. 1000 rpm. 30 bar of supply pressure. Input at node 26 (dof 101) and output at node 23 (node $89)$.

torsional movements of the foundation, which indeed are linked through the housing stiffeners and boosted at higher pressures. Given the existence of this unmodelled dynamic present in the LQG regulator, it was not possible to apply the complete control signals to both servovalves for pressure over 50 bar, cases for which control signals were reduced by a master gain to $40 \%$. Figure 14 depicts the same results as in Figure 9 but with a supply pressure of $30 \mathrm{bar}$, showing that with a less aggressive controller in terms of pressure, a good balance between the two resonant zones around $40 \mathrm{~Hz}$ and $90 \mathrm{~Hz}$ can be obtained. 


\section{Conclusions}

In this work, the design and implementation of model-based controllers for developing the feedback-controlled lubrication in actively-lubricated TPJBs were presented. The work demonstrates flexible rotor systems supported by the mentioned kind of bearings. The designed controllers are full-state optimal LQG controllers which harness the characteristics of LQR regulators with stochastic Kalman filters. Despite the results being obtained under operational conditions less demanding than those imposed on industrial machinery, results are valuable since they pinpoint latent problems when it comes to real applications. In the light of the simulations and the experimental campaigns, it can be concluded that:

- The current maturity in the modelling of actively-lubricated TPJBs based on the ETHD approach allows us to include full matrices of the bearing dynamic properties in the rotor-bearing modelling to design and develop model based controllers.

- The design of model-based controllers based on full state-feedback requires a model reduction. An appropriate reduction scheme is the pseudo-modal, which preserves only the slowest eigenvalues. A further treatment of complex states is also required in order to implement discrete controllers in processing units. Such a complex separation requires only complex conjugated eigenvalues in the frequency range of interest to be considered. Disregarding in advance real eigenvalues, does not pose a problem when dealing with the LQR regulator since it has the same effect as not weighting them with the modes weighting matrix.

- The LQG controller is a suitable option for developing feedback-controlled lubrication in active TPJBs since it allows us to focus the actuator energy in the modes of interest, such as bending modes of the rotor machine. It can be designed during the machine design process. Caution is advised when selecting the state or process noise, which might be backed up with simulations.

- From an experimental viewpoint, it was shown that the LQG controller performs well for the dynamics it was designed for, i.e., the first bending of the rotor-bearing system. This entails that the controller can be jointly

designed with bearings from the first stages of the bearing design and manufacturing. 
- Despite the effectiveness shown by the LQG regulator, it appeared obvious that a more accurate model which describes the dynamics of the rotorbearing system and also the foundation dynamics is needed. The modalreduced dynamics of the foundation must be incorporated in the modelling, so that bending and especially torsional movements can be incorporated. Further studies will target proper modelling, reducing and including the flexible foundation dynamics.

- Additional reduction of vibrations is obtained with the feedback-controlled lubrication over the hybrid and passive ones. Although PID controllers already deliver good results in a wider frequency range, they are suitable only as a post-production approach. In order to transform the active TPJB into an end-user machine element, efforts toward model-based controllers must be aimed.

Alternatively, and as a future work, robust $H_{\infty}$ controllers may also be approached under an optimization standpoint, so that discrepancies between theory and experiment can be treated as uncertainty for improved closed-loop stability.

\section{References}

[1] Thomsen K, Andersen H. Experimental investigation of a simple squeeze film damper. Journal of Engineering for Industry 1974; 96(2): 427-430.

[2] Vance JM, Li J. Test results of a new damper seal for vibration reduction in turbomachinery. In: ASME 1995 International Gas Turbine and Aeroengine Congress and Exposition, American Society of Mechanical Engineers 1995; p. V005T14A001.

[3] Ulbrich H, Althaus J. Actuator Design for Rotor Control. In: 12th Biennial conference on Mechanical Vibration and Noise. Montreal, Quebec, Canada, 1989; p. 17-22.

[4] Palazzolo A, Lin RR, Alexander RM, Kascak A, Montague J. Test and Theory for Piezoelectric Actuator-Active Vibration Control of Rotating Machinery. Journal of Vibration and Acoustics 1991; 113 (April): 167175 . 
[5] Althaus J, Ulbrich H. A fast hydraulic actuator for active vibration control. In: IMechE 1992, C432/045, 1992, p. 141-148.

[6] Burrows C, Keogh P, Tasaltin R. Closed-loop vibration control of flexible rotors-an experimental study. Proceedings of the Institution of Mechanical Engineers, Part C: Journal of Mechanical Engineering Science 1993; 207(1): 1-17.

[7] Koroishi EH, Borges AS, Cavalini AA, Steffen V. Numerical and experimental modal control of flexible rotor using electromagnetic actuator. Mathematical Problems in Engineering 2014; (2014): 361418.

[8] Chasalevri A, Dohnal F. Improving stability and operation of turbine rotors using adjustable journal bearings. Tribology International 2016; 104(12): 369-382.

[9] Pierart FG, Santos IF. Active lubrication applied to radial gas journal bearings. part 2: Modelling improvement and experimental validation. Tribology International 2016; 96: 237-246.

[10] Santos IF. Design and evaluation of two types of active tilting pad journal bearings. In: IUTAM Symposium on Active Control of Vibration 1994; 55: p. 583-594.

[11] Santos IF. On the Adjusting of the Dynamic Coefficients of Tilting-Pad Journal Bearings. STLE Tribology Transactions 1995; 38(3): 700-706.

[12] Santos IF. Theoretical and Experimental Identification on the Stiffness and Damping Coefficients of Active-Tilting Pad Journal Bearings, in: M. Friswell, M. J.E. (Eds.), Identification in Engineering Systems, The Cromwell Press Ltd., Swansea,Great Britain, 1996; p. 325-334.

[13] Cai Z, De Queiroz M, Khonsari M. On the active stabilization of tiltingpad journal bearings. Journal of Sound and Vibration 2004; 273(1): 421-428.

[14] Santos IF, Russo F. Tilting-pad journal bearings with electronic radial oil injection. Journal of Tribology 1998; 120(3): 583-594.

[15] Deckler D, Veillette R, Braun M, Choy F. Simulation and Control of an Active Tilting-Pad Journal Bearing. STLE Tribology Transactions 2004; 47(3): 440-458. 
[16] Hagg AC. The influence of oil-film journal bearings on the stability of rotating machines. Journal of Applied Mechanics, Transactions of the ASME 1946; 13(3): A211-A220.

[17] Pope A, Healy A. Paper 11: Anti-vibration journal bearings. In: Proceedings of the Institution of Mechanical Engineers, Conference Proceedings, SAGE Publications 1966; 181: p. 98-115.

[18] Salazar JG, Santos IF. Exploring integral controllers in activelylubricated tilting-pad journal bearings. Proc IMechE Part J: J Engineering Tribology 2015; 229(7): 835-848.

[19] Salazar JG, Santos IF. Feedback-controlled lubrication for reducing the lateral vibration of flexible rotors supported by tilting-pad journal bearings. Proc IMechE Part J: J Engineering Tribology 2015; 229(10): 12641275 .

[20] Santos IF, Scalabrin A. Control System Design for Active Lubrication With Theoretical and Experimental Examples. Journal of Engineering for Gas Turbines and Power 2003; 125(1): 75-80.

[21] Nicoletti R, Santos IF. Linear and Non-Linear Control Techniques Applied to Actively Lubricated Journal Bearings, Journal of Sound and Vibration 2003; 260(5): 927-947.

[22] Santos IF, Nicoletti R, Scalabrin A. Feasibility of Applying Active Lubrication to Reduce Vibration in Industrial Compressors. Journal of engineering for Gas Turbines and Power 2004; 126 (October): 848-854.

[23] Nicoletti R, SantosIF. Frequency Response Analysis of an Actively Lubricated Rotor/Tilting-Pad Bearing System. ASME Journal of Engineering for Gas Turbines and Power 2005; 127: 638-645.

[24] Lund J. Spring and Damping for the Tilting-Pad Journal Bearings. ASLE Transactions 1964; 7(4): 342-352.

[25] Allaire P, Parsell J, Barrett L. A Pad Perturbation Method for the Dynamic Coefficients of Tilting-Pad Journal Bearings. Wear 1981; 72(1): $29-44$. 
[26] Earles L, Palazzolo A, Armentrout R. A Finite Element Approach to Pad Flexibility Effects in Tilting Pad Journal Bearings: Part I - Single Pad Analysis. ASME Journal of Tribology 1990; 112(2): 169-176.

[27] Earles L, Palazzolo A, Armentrout R.A Finite Element Approach to Pad Flexibility Effects in Tilting Pad Journal Bearings: Part II - Assembled Bearing and System Analysis. ASME Journal of Tribology 1990; 112(2): 178-182.

[28] Fillon M, Bligoud JC, Frêne J. Experimental Study of Tilting-Pad Journal Bearings - Comparison with Theoretical Thermoelastohydrodynamic Results. ASME Journal of Tribology 1992; 114: 579-588.

[29] Knight J, Barrett L. Analysis of Tilting Pad Journal Bearings with Heat Transfer Effects. ASME Journal of Tribology 1988; 110: 128-133.

[30] Santos IF, Nicoletti R. THD analysis in tilting-pad journal bearings using multiple orifice hybrid lubrication, Journal of Tribology 1999; 121(4): 892-900.

[31] Haugaard AM, Santos IF. Elastohydrodynamics applied to active tiltingpad journal bearings. Journal of Tribology 2010; 132(2): 021702.

[32] Varela AC, Nielsen BB, Santos IF. Steady state characteristics of a tilting pad journal bearing with controllable lubrication: Comparison between theoretical and experimental results. Tribology International 2013; 58(1): 85-97.

[33] Varela AC, Santos IF. Dynamic coefficients of a tilting pad with active lubrication: Comparison between theoretical and experimental results. Journal of Tribology 2015; 137(3): 031704.

[34] Firoozian R, Stanway R. Active vibration control of turbomachinery: A numerical investigation of modal controllers. Mechanical Systems and Signal Processing 1988; 2(3): 243-264.

[35] Rosyid A, ElMadany M, Alata M. Optimal control of reduced-order finite element models of rotor-bearing-support systems. Journal of the Brazilian Society of Mechanical Sciences and Engineering 2015; 37(5): 1485-1497. 
[36] Nicoletti R, Santos IF. Control System Design for Flexible Rotors Supported by Actively Lubricated Bearings, Journal of Vibration and Control 2008; 14 (3): 347-374.

[37] Hendricks E, Jannerup OE, Sørensen PH. Linear Systems Control. Technical University of Denmark, Ørsted, Automation, 2005.

[38] Hamdan A, Nayfeh A. Measures of Modal Controllability and Observability for First- and Second-Order Linear Systems, Journal of Guidance Control and Dynamics 1989; 12(3): 421-428.

[39] Christensen RH, Santos IF. Design of active controlled rotor-blade systems based on time-variant modal analysis. Journal of sound and vibration 2005; 280(3): 863-882.

[40] Salazar JG, Santos IF. On the controllability and observability of actively-lubricated journal bearings with pads with different nozzle-pivot configurations. ASME Journal of Tribology 2017; 139(3): 031702.

[41] Skogestad S, Postlethwaite I. Multivariable feedback control: analysis and design, Vol. 2, Wiley New York, 2007.

[42] Lauridsen JS, Sekunda AK, Santos IF, Niemann H. Identifying parameters in active magnetic bearing system using $\mathrm{ft}$ formulation and youla factorization. In: Control Applications (CCA), 2015 IEEE Conference 2015; p. 430-435.

[43] Luenberger D. An introduction to observers. IEEE Transactions on automatic control 1971; 16(6): 596-602.

[44] Kalman RE. A new approach to linear filtering and prediction problems. Transactions of the ASME-Journal of Basic Engineering 1960; 82 (Series D): $35-45$. 